\title{
Preliminary Designing Method of External Pressure Vessels for Sea Subsurface Applications
}

\author{
Jan P. Michalski, Assoc. Prof. \\ Gdansk University of Technology \\ Polish Naval University
}

\author{
ABSTRACT
}

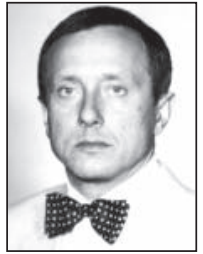

This paper describes a unique engineering method intended for the preliminary designing of marine echo-location systems. The solved designing problem consists in determining geometrical parameters and selecting structural materials for a vessel of a buoyancy necessary to contain measuring instruments of a given mass, as well as its maximum gabarites and operational submersion depth. The assumed variability range of the system's parameters determines a space of permissible applicability parameters of the method. Stress level related to permissible and critical stresses was assumed to be safety criterion for the vessel. The method may be applied also to solving converse problems consisting in determining maximum permissible submersion depth for a vessel made of assumed structural materials and having given geometrical parameters. The presented description of the method is illustrated by an example of its application.

Keywords: subsurface buoy mooring systems; external pressure vessels

\section{INTRODUCTION}

Tight submerssible vessels intended for the fulfilling of assumed functions deep in water, capable of carrying large external hydrostatic loads find many civil and military applications such as submarines and submersible vehicles, bathyscaphes, crude-oil and gas storage tanks, or casings for measurement apparatus to conduct underwater oceanological experiments [3]. For example, the measuring, recording and investigating of physical fields of seas and oceans is conducted by means of echo-location systems (Subsurface buoy mooring systems) composed of such elements as:

- floats (buoys of a required buoyancy)

- vessels containing measuring and recording apparatus

- vessels containing electric storage batteries

- anchoring device in the form of ballast

- tension members joining elements of a module.

The system's elements are connected to each other by means of elastic tension members, i.e. cables or chains. The vessel's shell plating is loaded by hydrostatic pressure proportional to submersion depth, sometimes also by a hydrodynamic load due to water current or surface wave motion. Also, concentrated loads generated by tension members are applied to the vessel. For functional reasons the vessel's structure should ensure its buoyancy, shape and watertightness to be maintained.

This paper contains a description of the engineering method for the preliminary designing of echo-location system, which serves to determining design solutions satisfying a set of functional, technological and mechanical assumptions. Original algorithms for the determining of parameters of vessels subjected to action of external pressure - in the aspect of their buoyancy, shell structure strength and form stability - are also presented in it.

Applicability of the method is determined by ranges of permissible values of vessel's form parameters, external pressure values as well as a kind of structural material. The method may be useful in particular for the preliminary designing of echo-location systems (Subsurface buoy mooring systems) within the area of:

- designing their geometrical configuration

- designing geometrical parameters of their vessels

- selection of their structural materials

- assessment of quantity of their mass

- determining optimum design solutions in an assumed sense.

\section{FORMULATION OF DESIGNING PROBLEM}

The designing problem consists in determining geometrical parameters and selection of a structural material for a vessel of a given effective buoyancy, capable of accommodating measurement apparatus of a given mass and dimensions, at a given operational submersion depth. Variability range of parameters for which calculation algorithms of the method have been elaborated, determines a space of permissible parameters for its application. The method makes it possible to solve also converse problems, namely determination of a maximum 
permissible submersion depth of a vessel made of a given structural material and having given geometrical parameters.

An axially symmetrical vessel is considered of empty interior (a float) or containing measurement apparatus of the mass $m_{a}$ and maximum linear dimension 1 ; a part of the vessel can be filled with a lightweight material, e.g. polyurethane foam in order to maintain buoyancy of the vessel in the case of flooding its interior by water due to damage or loss of watertightness of its shell plating. The effective displacement $\mathrm{D}_{\mathrm{e}}$ of the vessel of the volume $\mathrm{V}$, plating surface area $\mathrm{S}$ and constant shell plating thickness $h$, immersed in water of the constant density $\rho_{w}$, is described by the buoyancy equation in which:

- $\alpha=0$ - in the case of keeping the vessel tight

$-\alpha=1-$ in the case of flooding the vessel entirely

$D_{e}=(1-\alpha) \cdot \rho_{\mathrm{w}} \cdot V+\alpha \cdot \rho_{\mathrm{w}} \cdot\left(\frac{\mathrm{m}_{\mathrm{a}}}{\rho_{\mathrm{a}}}+\frac{\mathrm{m}_{\mathrm{f}}}{\rho_{\mathrm{f}}}+\mathrm{S} \cdot \mathrm{h}\right)+$

where:

$$
-\left(m_{v}+m_{a}+m_{f}\right) \pm \frac{F_{z}}{g}
$$

g - gravity acceleration

$\mathrm{m}_{\mathrm{v}}$ - mass of vessel plating

$\rho_{v}-$ density of vessel plating material

$\mathrm{m}_{\mathrm{a}}$ - mass of apparatus

$\rho_{\mathrm{a}}-$ average density of apparatus

$\mathrm{m}_{\mathrm{f}}$ - mass of filler

$\rho_{\mathrm{f}}-$ density of filler (foam)

$\mathrm{F}_{\mathrm{z}}-\quad$ value of external concentrated load

Balance of components of mass and displacement of vessel in Eq. (1) can be described by the following important design parameters of the system:

- the geometrical parameters of the vessel, V, S, h

- the density of structural material of its shell plating, $\rho_{v}$

- the mass of apparatus inside the float, $m_{a}$, and its average density $\rho_{\mathrm{a}}$

- the maximum linear dimension of the apparatus, $l_{\mathrm{a}}$

- the filler volume $V_{f}$ and its density $\rho_{f}$

- value of the external load $\mathrm{F}_{\mathrm{z}}$

The balance equation is then expressed by the equivalent relation as follows:

$$
\begin{gathered}
\mathrm{D}_{\mathrm{e}}=(1-\alpha) \cdot \rho_{\mathrm{w}} \cdot \mathrm{V}+\alpha \cdot \rho_{\mathrm{w}} \cdot\left(\frac{\mathrm{m}_{\mathrm{a}}}{\rho_{\mathrm{a}}}+\mathrm{V}_{\mathrm{f}}+\mathrm{S} \cdot \mathrm{h}\right)+ \\
-\mathrm{S} \cdot \mathrm{h} \cdot \rho_{\mathrm{p}}-\mathrm{m}_{\mathrm{a}}-\mathrm{V}_{\mathrm{f}} \cdot \rho_{\mathrm{f}} \pm \frac{\mathrm{F}_{\mathrm{z}}}{\mathrm{g}}
\end{gathered}
$$

Positive value of the right-hand side of Eq.(2) as well as positive sign of the external load Fz stands for senses of forces opposite to gravity force. In Eq. (2) the belonging of parameters either to the set of the parameters to be determined or that of given ones constitutes a tag of variant of the method for preliminary designing the float. To achieve an effective solution of Eq. (2) it is necessary to add complementary equations whose set and genealogy constitute another tag of the designing method. In the case of the method formulated in the form of an optimization problem Eq. (2) should be complemented by:

- a criterion of choice of an optimum solution

- a set of inequalities which restrain allowable solutions.

The elaborated calculation algorithms of the method concern the designing process of vessels having axially symmetrical shells of circular cross-section, made of:
- NW 210 steel of normal strength

- AL 5085 aluminium alloy usually applied in shipbuilding.

The range of permissible parameters of the method in question was so selected as to make it possible to obtain geometrical dimensions, form proportions, structural material as well as maximum operational submersion depth which would satisfy requirements for echo-location research systems for Baltic Sea environment.

A hazard to structural safety of a vessel subjected to action of high external pressure may result either from exceedance of reduced permissible stresses or critical stresses leading to loss of form stability (buckling) of its shell plating [1, 2, 4], in consequence to loss of its functional qualities. The method in question covers the whole range of elastic deformations up to the material yield point $\mathrm{R}_{\mathrm{e}}$; the vessel's parameters are so determined as to obtain reduced stresses as well as critical stresses which do not exceed their permissible values at an external load enlarged by safety factor.

\section{ASSUMPTIONS AND GEOMETRICAL DESCRIPTION OF FORM OF VESSEL}

Vessel's shell plating is composed of a cylindrical casing of circular cross-section closed by two bottoms of a specific form which ensures moment-less state of stresses in the shell plating. The choice of such form of the vessel results from its usefulness to accommodate measurement apparatus and a simpler process of its manufacturing in contrast to spherical vessels. In accordance with the linear theory of stability of thin-walled elastic shells permissible values of the vessel plating thickness $h$ were assumed much smaller than the curvature radius $\mathrm{R}$ of shell casing. Effects of possible geometrical imperfections of shell form were taken into account by safety factor increasing calculation external loads. The shell surface area of the vessel is assumed the same as the middle surface area of the shell plating. Structural mathematical models for determining structural strength and stability of shells as well as reccommended values of safety factors were taken from the respective subject-matter literature sources $[1,2,3,4]$.

\section{Form of bottom's surface}

The bottoms constitute support for vessel casing loaded by constant pressure. The desired momentless state of internal forces in shell plating will occur at an appropriate form of the bottoms. In the case of convex bottoms such form can be described by an appropriate plane curve (directrix) whose rotation around cylinder's axis generates, at vessel's bottom/ shell casing contact, a surface of the circumferential curvature radius $\mathrm{R}_{\varphi}=\mathrm{R}$ and axial curvature radius $\mathrm{R}_{\mathrm{z}}=\infty$, which are consistent with curvatures of the shell casing. The requirement is fulfilled by the bottom surface of the directrix described by the following relation [4]:

$$
\zeta=\left(1-\xi^{2}\right)^{\frac{1}{t}}=\left[1-\left(\frac{r}{R}\right)^{2}\right]^{\frac{1}{t}}
$$

where:

$\mathrm{t} \in \mathbf{R}>2.0$ - index exponent - a real number

$\xi=\frac{r}{R} \quad-$ dimensionless radius of vessel, $0 \leq \xi \leq 1$

$\zeta=\frac{Z}{1_{d}} \quad-$ dimensionless camber of bottom, $1 \leq \xi \leq 0$

$1_{d} \quad-$ camber of bottom. 


\section{Area of bottom's surface}

Bottom's surface area constitutes a part of vessel's shell area and affects quantity of shell plating mass. The bottom's surface area $\mathrm{S}_{\mathrm{d}}$ can be expressed by using Guldin theorem:

$$
S_{d}=2 \cdot \pi \cdot \int_{0}^{\mathrm{R}} \mathrm{r} \cdot \sqrt{1+\left(\frac{\mathrm{dz}}{\mathrm{dr}}\right)^{2}} \cdot \mathrm{dr}
$$

and after substituting dimensionless variables:

$$
\begin{gathered}
\mathrm{S}_{\mathrm{d}}=2 \cdot \pi \cdot \mathrm{R}^{2} \cdot \int_{0}^{1} \xi \cdot \sqrt{1+\left(\frac{\mathrm{l}_{\mathrm{d}}}{\mathrm{R}}\right)^{2} \cdot\left(\frac{\mathrm{d} \zeta}{\mathrm{d} \zeta}\right)^{2}} \cdot \mathrm{d} \xi= \\
=2 \cdot \pi \cdot \mathrm{R}^{2} \cdot \int_{0}^{1} \mathrm{~s}\left(\xi ; \mathrm{R}, \mathrm{l}_{\mathrm{d}}, \mathrm{t}\right) \cdot \mathrm{d} \xi
\end{gathered}
$$

Inverse function of the integral is not known hence it cannot be expressed by an analytical formula. In order to elaborate a simple approximating formula useful in formulating Eq. (2), parametric investigations of numerical values of the integral were conducted within the following ranges of the parameters: $0 \leq 1_{\mathrm{d}} / \mathrm{R} \leq 0.5$ and $2.5 \leq \mathrm{t} \leq 4.5$, by using the quadrature [6]:

$$
\mathrm{S}_{\mathrm{d}}\left(\mathrm{R}, \frac{\mathrm{l}_{\mathrm{d}}}{\mathrm{R}}, \mathrm{t}\right) \cong 2 \pi \frac{\Delta \mathrm{R}}{2}\left(\mathrm{~S}_{\xi=0}+\mathrm{S}_{\xi=1}+2 \sum_{\mathrm{i}=1}^{\mathrm{N}} \mathrm{S}_{\xi=\mathrm{i}} \frac{\Delta \mathrm{R}}{\mathrm{R}}\right)
$$

The best obtained analytical approximation of discrete values of the quadrature is represented by the expression [6]:

$$
\begin{gathered}
\mathrm{S}_{\mathrm{d}}\left(\mathrm{R}, \frac{1_{\mathrm{d}}}{\mathrm{R}}, \mathrm{t}\right) \cong \pi \cdot \mathrm{R}^{2} \cdot\left[1+\mathrm{c}_{1} \cdot\left(\frac{\mathrm{l}_{\mathrm{d}}}{\mathrm{R}}\right)^{\mathrm{c}_{2}} \cdot \mathrm{t}^{\mathrm{c}_{3}}\right]= \\
=\pi \cdot \mathrm{R}^{2} \cdot\left[1+0.4281 \cdot\left(\frac{1_{\mathrm{d}}}{\mathrm{R}}\right)^{1.411} \cdot \mathrm{t}^{0.4862}\right]
\end{gathered}
$$

Within the considered variability range of the investigated parameters the relative percentage error of values of the integral determined by means of Eq. (7) and the quadrature (6), does not exceed $0.3 \%$.

\section{Bottom's volume}

Volume of the bottoms which constitutes a part of the vessel volume, affects value of its displacement. The bottom volume can be determined by using the Guldin theorem:

$$
\mathrm{V}_{\mathrm{d}}=2 \pi \cdot 1_{\mathrm{d}} \cdot \int_{0}^{\mathrm{R}} \mathrm{r} \cdot\left(1-\left(\frac{\mathrm{r}}{\mathrm{R}}\right)^{2}\right)^{\frac{1}{\mathrm{t}}} \mathrm{dr}
$$

In the case of the considered form of the bottom the integral is non-infinitesimal, as its primitive function is not known. By substituting the dimensionless variables $\mathrm{r}=\mathrm{R} \cdot \xi$ and $\mathrm{dr}=\mathrm{R} \cdot \mathrm{d} \xi$ the following is achieved:

$$
\begin{aligned}
\mathrm{V}_{\mathrm{d}} & =2 \pi \cdot 1_{\mathrm{d}} \cdot \mathrm{R}^{2} \cdot \int_{0}^{1} \xi \cdot\left(1-\xi^{2}\right)^{\frac{1}{\mathrm{t}}} \mathrm{d} \xi= \\
& =2 \cdot \pi \cdot \frac{1_{\mathrm{d}}}{\mathrm{R}} \cdot \mathrm{R}^{3} \cdot \int_{0}^{1} \mathrm{v}(\xi, \mathrm{t}) \cdot \mathrm{d} \xi
\end{aligned}
$$

In order to elaborate a simple approximating formula useful in formulating Eq. (2), parametric investigations of numerical values of the integral were conducted within the following ranges of the parameters: $0 \leq 1_{d} / R \leq 0.5$ and $2.5 \leq t \leq 4.5$, by using the quadrature [6]:

$\mathrm{V}_{\mathrm{d}}\left(\mathrm{R}, \frac{1_{\mathrm{d}}}{\mathrm{R}}, \mathrm{t}\right) \cong 2 \cdot \pi \cdot \frac{\Delta \mathrm{R}}{2} \cdot\left(\mathrm{V}_{\xi=0}+\mathrm{V}_{\xi=1}+2 \cdot \sum_{\mathrm{i}=1}^{\mathrm{N}} \mathrm{V}_{\xi=\mathrm{i}} \frac{\Delta \mathrm{R}}{\mathrm{R}}\right)$ (10)

On the basis of the obtained numerical values,by testing various hypotheses on a form of approximating functions, the following analytical formula for approximate determination of values of bottom's volume was elaborated [6]:

$$
\begin{gathered}
\mathrm{V}_{\mathrm{d}}\left(\mathrm{R}, \frac{1_{\mathrm{d}}}{\mathrm{R}}, \mathrm{t}\right) \cong \mathrm{c}_{1} \cdot \pi \cdot \frac{1_{\mathrm{d}}}{\mathrm{R}} \cdot \mathrm{t}^{\mathrm{c}^{2}} \cdot \mathrm{R}^{3}= \\
\quad=0.5747 \cdot \pi \cdot \frac{1_{\mathrm{d}}}{\mathrm{R}} \cdot \mathrm{t}^{0.2339} \cdot \mathrm{R}^{3}
\end{gathered}
$$

Within the considered variability range of the investigated parameters the relative percentage error of values of the integral determined by means of Eq. (11) and the quadrature (10), does not exceed $0.3 \%$.

The complementary part of the whole volume of the vessel, $\mathrm{V}$, is the following volume of its cylindrical part, $\mathrm{V}_{\mathrm{c}}$, of the length L:

$$
\mathrm{V}_{\mathrm{c}}=2 \pi R L^{\wedge} \mathrm{V}=2 \mathrm{~V}_{\mathrm{d}}+\mathrm{V}_{\mathrm{c}}
$$

\section{CRITERION OF STRUCTURAL STRENGTH SAFETY}

As a measure of material effort of structure under external load the reduced stresses are assumed usually in compliance with Mises-Huber hypothesis expressed as follows:

$$
\sigma_{\text {red }}=\frac{1}{\sqrt{2}}
$$

$$
\cdot \sqrt{\left(\sigma_{x}-\sigma_{y}\right)^{2}+\left(\sigma_{y}-\sigma_{z}\right)^{2}+\left(\sigma_{z}-\sigma_{x}\right)^{2}+6 \cdot\left(\tau_{x y}^{2}+\tau_{y z}^{2}+\tau_{z x}^{2}\right)}
$$

In the case of thin-walled shells (of $\mathrm{R} / \mathrm{h}>20$ ) under momentless load their state of stress can be considered twodimensional, in this case the reduced stresses can be expressed by the principal stresses: axial ones, $\sigma_{\mathrm{z}}$, and circumferential ones, $\sigma_{\varphi},[4]$ :

$$
\sigma_{\text {red }}=\sqrt{\sigma_{z}^{22}+\sigma_{\varphi}-\sigma_{z} \cdot \sigma_{\varphi}}
$$

Structural strength safety is determined by the condition of maintaining the reduced stresses in the shell plating smaller than the permissible ones. Value of the permissible stresses related to the structural material yield point $R_{e}$, was obtained by assuming the safety factor $n_{\mathrm{s}}>1$ of a value determined according to a standard, rules, or on the basis of experimental knowledge or empirical practice:

$$
\sigma_{\max } \leq \sigma_{\text {per }}=\frac{\mathrm{R}_{\mathrm{e}}}{\mathrm{n}_{\mathrm{s}}}
$$

Depending on a required reliability of a device,value of the safety factor is contained within the range of: $\mathrm{n}_{\mathrm{s}}=1.1 \div 20$, and usually: $\mathrm{n}_{\mathrm{s}}=2.5 \div 4.0[1,2,3,4]$. Hence the structural strength safety condition takes the following form:

$\sigma_{\text {red max }}=\max \left(\sqrt{\sigma_{z}^{22}+\sigma_{\varphi}-\sigma_{z} \cdot \sigma_{\varphi}}\right) \leq \sigma_{\text {per }}=\frac{R_{e}}{n_{s}}$ 
In momentless state of stress vessel's shell plating is compressed simultaneously by uniformly distributed axial and circumferential forces. Unit compression forces in vessel's casing are determined by the following relations:

- axial force per unit length of vessel's circumference:

$$
\mathrm{N}_{\mathrm{z}}=\frac{\mathrm{F}}{2 \cdot \pi \cdot \mathrm{R}}=\frac{\pi \cdot \mathrm{R}^{2} \cdot \mathrm{p}-\mathrm{F}_{\mathrm{z}}}{2 \cdot \pi \cdot \mathrm{R}} \cong 0.5 \cdot \mathrm{R} \cdot \mathrm{p}
$$

- circumferential force per unit length of vessel's directrix:

$$
\mathrm{N}_{\varphi}=\frac{\mathrm{F}}{2 \cdot \mathrm{R}}=\frac{2 \cdot \mathrm{R} \cdot \mathrm{L} \cdot \mathrm{p}}{2 \cdot \mathrm{L}}=\mathrm{R} \cdot \mathrm{p}
$$

The principal axial stresses are determined by the relation:

$$
\sigma_{\mathrm{z}}=\frac{\pi \cdot \mathrm{R}^{2} \cdot \mathrm{p}-\mathrm{F}_{\mathrm{z}}}{2 \cdot \pi \cdot \mathrm{R} \cdot \mathrm{h}} \cong 0.5 \cdot \frac{\mathrm{R}}{\mathrm{h}} \cdot \mathrm{p}
$$

The principal circumferential stresses by the relation:

$$
\sigma_{\varphi}=\frac{2 \cdot \mathrm{R} \cdot \mathrm{p} \cdot \mathrm{L}}{2 \cdot \mathrm{L} \cdot \mathrm{h}}=\frac{\mathrm{R}}{\mathrm{h}} \cdot \mathrm{p}
$$

If vessel load changes occur slowly then dynamic and fatigue loads can be neglected, and the structural strength safety criterion for vessel under uniform external pressure is determined by the relation:

$$
\begin{gathered}
\sigma_{\text {red max }}=\max \left(\sqrt{\sigma_{\mathrm{z}}^{2}+\sigma_{\varphi}^{2}-\sigma_{\mathrm{z}} \cdot \sigma_{\varphi}}\right)= \\
=\frac{\sqrt{3}}{2} \cdot \frac{\mathrm{R}}{\mathrm{h}} \cdot \mathrm{p}_{\max } \leq \sigma_{\mathrm{per}}=\frac{\mathrm{R}_{\mathrm{e}}}{\mathrm{n}_{\mathrm{s}}}
\end{gathered}
$$

\section{CRITERION OF FORM STABILITY SAFETY}

Static stability of shell form means that there is an equilibrium state in a position neighbouring to the considered. The state of static equilibrium of form of axially symmetrical vessel under constant external load at momentless state of stress and linear elastic strain is described by the deformation form function $\mathrm{w}=\mathrm{w}(\mathrm{z}, \varphi)$ which is solution of shell form stability equation. Depending on parameters of a vessel, loss of form stability may take mode of axial or circumferential buckling. Form deformation depends on values of geometric and material parameters of a vessel and mode of its loading. The parameters constitute arguments of differential equation of shell stability. Under certain simplifying assumptions the form stability equation of cylindrical shell takes the following form [4]:

$$
\begin{aligned}
\mathrm{D} \cdot \nabla^{8} \mathrm{w} & +\frac{\mathrm{E} \cdot \mathrm{h}}{\mathrm{R}^{2}} \cdot \frac{\partial^{4} \mathrm{w}}{\partial \mathrm{z}^{4}}+\frac{1}{2} \cdot \mathrm{p} \cdot \mathrm{R} \cdot \nabla^{4}\left(\frac{\partial^{2} \mathrm{w}}{\partial \mathrm{z}^{2}}\right)+ \\
& +\mathrm{p} \cdot \mathrm{R} \cdot \nabla^{4}\left(\frac{\partial^{2} \mathrm{~W}}{\mathrm{R}^{2} \cdot \partial \varphi^{2}}\right)=0
\end{aligned}
$$

where:

$\mathrm{D}=\frac{\mathrm{E} \cdot \mathrm{h}^{3}}{121 \cdot\left(1-v^{2}\right)}-$ shell stiffness

$\nabla^{4} \mathrm{~W}=\frac{\partial^{4} \mathrm{w}}{\partial \mathrm{z}^{4}}+\frac{2}{\mathrm{R}^{2}} \frac{\partial^{4} \mathrm{w}}{\partial \mathrm{z}^{2} \cdot \partial \varphi^{2}}+\frac{1}{\mathrm{R}^{4}} \cdot \frac{\partial^{4} \mathrm{~W}}{\partial \varphi^{4}}$

Eq. is solved by assuming a priori a form of allowable function which satisfies relevant boundary conditions of deformation:

$$
\mathrm{W}=\overline{\mathrm{W}} \cdot \sin \frac{\pi \cdot \mathrm{m} \cdot \mathrm{z}}{\mathrm{L}} \cdot \cos \mathrm{n} \cdot \varphi
$$

where:

$\overline{\mathrm{W}}$ - shell deflection

$\mathrm{m}$ - number of longitudinal half-waves of shell deformation

$\mathrm{n}$ - number of circumferential waves of shell deformation.

On substitution of the allowable function to Eq. (22) the algebraic equation of deformations is obtained as follows:

$$
\begin{gathered}
\frac{\overline{\mathrm{W}}}{\mathrm{R}^{62}}\left\{\frac{\mathrm{D}}{\mathrm{R}} \cdot\left[\left(\pi \cdot \mathrm{m} \frac{\mathrm{R}}{\mathrm{L}}\right)^{2}+\mathrm{n}^{2}\right]^{4}+\mathrm{E} \cdot \mathrm{h}\left(\pi \cdot \mathrm{m} \frac{\mathrm{R}}{\mathrm{L}}\right)^{4}+\right. \\
\left.-\mathrm{p} \cdot \mathrm{R} \cdot\left[\frac{1}{2}\left(\pi \cdot \mathrm{m} \frac{\mathrm{R}}{\mathrm{L}}\right)^{2}+\mathrm{n}^{2}\right] \cdot\left[\left(\pi \cdot \mathrm{m} \frac{\mathrm{R}}{\mathrm{L}}\right)^{2}+\mathrm{n}^{2}\right]^{2}\right\} . \\
\cdot \sin \frac{\pi \cdot \mathrm{m} \cdot \mathrm{z}}{\mathrm{L}} \cdot \cos (\mathrm{n} \cdot \varphi)=0
\end{gathered}
$$

The pressure at which the equation is fulfilled, is determined by the relation [4]:

$$
p_{m, n}=\frac{\frac{\left(s^{22}+n\right)^{4}}{121\left(1-v^{2}\right)}+s^{4} \cdot\left(\frac{R}{h}\right)^{2}}{\left(\frac{s^{2}}{2}+n^{2}\right) \cdot\left(s^{2}+n^{2}\right)^{2}} \cdot E \cdot\left(\frac{h}{R}\right)^{3}
$$

where:

$\mathrm{s}=\pi \cdot \mathrm{m} \cdot \frac{\mathrm{R}}{\mathrm{L}}$

The critical pressure at which a shell under uniform external load loses its form stability within elastic deformation range (i.e. suffers buckling), is equal to the smallest value of the pressures $p_{m, n}$ determined at the successively assumed integer numbers $m$ of longitudinal half-waves and $n$ numbers of circumferential waves, at fixed $R / L$ and $R / h$ ratios and the parameters $\mathrm{E}, \mathrm{V}$, at which relevant modes of form deformations take place, namely the critical pressure $\mathrm{p}_{\mathrm{cr}}$ :

$$
\mathrm{p}_{\mathrm{cr}}=\min _{\mathrm{m}, \mathrm{n}}\left\{\mathrm{p}_{\mathrm{m}, \mathrm{n}}\right\}
$$

where:

$\mathrm{m} \wedge \mathrm{n} \in \mathbf{N}$

\section{MINIMUM OF CRITICAL PRESSURE FUNCTIONAL}

Value of the critical pressure $\mathrm{p}_{\text {cr }}$ is equal to the global minimum value of critical pressure relevant to all possible modes of shell form deformations within permissible variability range of design parameters:

$$
\mathrm{p}_{\mathrm{cr}}=\min _{\mathrm{m}, \mathrm{n} \in \mathbf{N}} \mathrm{p}\left(\mathrm{m}, \mathrm{n}, \frac{\mathrm{R}}{\mathrm{L}}, \frac{\mathrm{R}}{\mathrm{h}}, \mathrm{v}, \mathrm{E}\right)
$$

The presented method concerns vessels of specific geometrical and material features which have been a priori assumed to be functionally useful [5], and the below given range of their variability determines the allowable applicability space of the method:

- the range of allowable values of the ratio $\mathrm{R} / \mathrm{L}$ :

$0.25 \leq \mathrm{R} / \mathrm{L} \leq 1\{0.25,0.5,1.0\}$; 
- the range of allowable values of the ratio $\mathrm{R} / \mathrm{h}$ : $25 \leq \mathrm{R} / \mathrm{h} \leq 150\{25,50,150\}$

- Poisson number v (for NW-steel and AL-5083 alloy): $\mathrm{v}=0.3$ and $\mathrm{v}=0.33$

- Young modulus E (for NW-steel and AL-5083 alloy): $\mathrm{E}=2.1 \cdot 10^{5}$ and $\mathrm{E}=0.72 \cdot 10^{5}[\mathrm{Mpa}]$

- the number of considered axial half-waves of deformation: $\mathrm{m}=1$

- the number of considered circumferential waves of deformation: $\mathrm{n}=3 \div 12$.

For the above given combinations of parameters the following was elaborated:

- discrete values of the critical pressure:

$$
\mathrm{p}_{\mathrm{cr}}=\min _{\mathrm{m}=1} \mathrm{p}_{\mathrm{n} \in\{1 \div 12\}}\left(\mathrm{m}, \mathrm{n}, \frac{\mathrm{R}}{\mathrm{L}}, \frac{\mathrm{R}}{\mathrm{h}}, v, \mathrm{E}\right)
$$

- diagrams of (continuous) functions of critical pressures [6], exemplified in Fig. 1

- from the diagrams was read a number of circumferential waves at which the critical pressure $p_{\text {cr }}$ reaches its smallest value, at constant values of the remaining parameters.

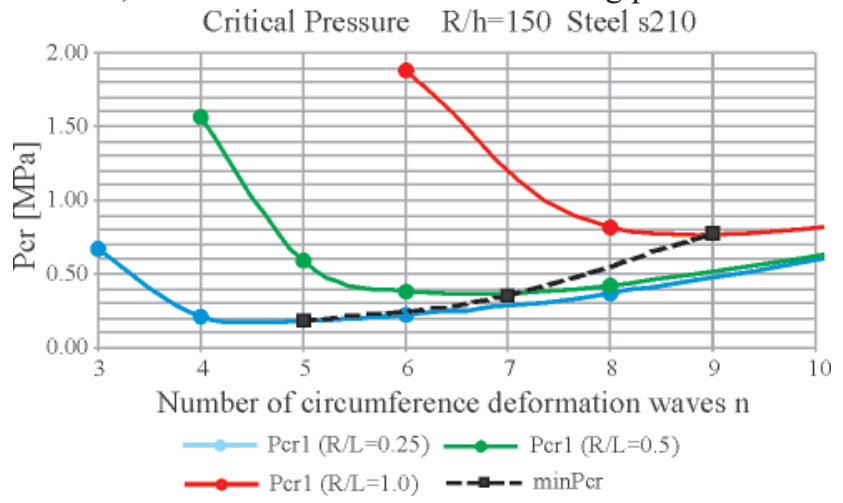

Fig. 1. Example of envelopes of the minimum critical pressure values [6]: $p_{c r}=p_{c r}\left(\frac{R}{L}, n ; m=1, \frac{R}{h}=150, E=2.1 \cdot 10^{5} \mathrm{MPa}, v=0.3\right)$

\section{APPROXIMATION OF CRITICAL PRESSURE}

On the basis of the set of discrete critical pressure values an analytical approximation formula minimizing the sum of squares of deviations, was elaborated. In the case of vessels made of NW-steel the best approximation of critical pressure is represented by the following expression [6]:

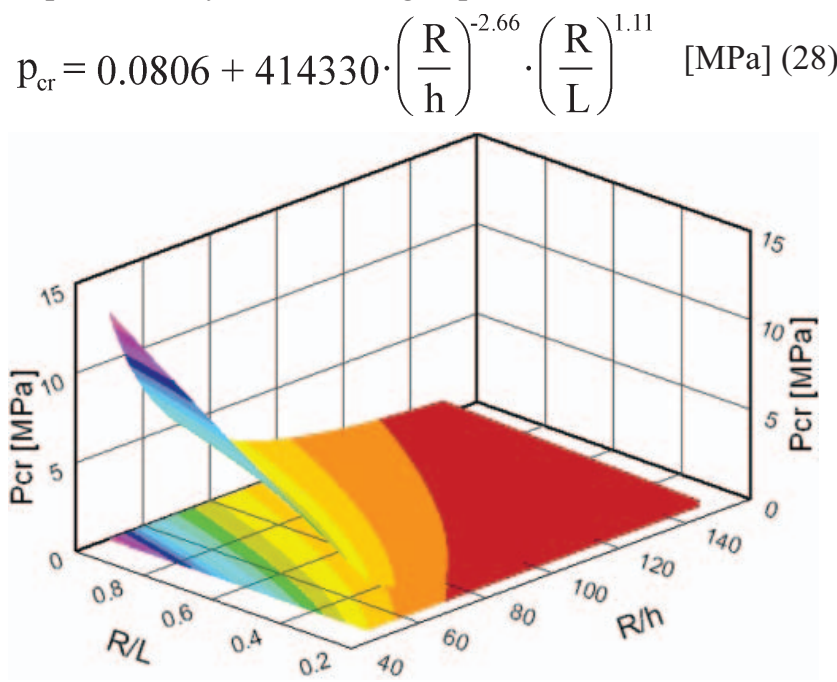

Fig. 2. Diagram of the relation $p_{c r}=f\left(\frac{R}{h}, \frac{R}{L}\right)$

- for structural material: $N W$-steel
In the case of AL-5083 alloy the best approximation of critical pressure is represented by the following expression [6]:

$$
\mathrm{p}_{\mathrm{cr}}=0.0262+139640 \cdot\left(\frac{\mathrm{R}}{\mathrm{h}}\right)^{-2.66} \cdot\left(\frac{\mathrm{R}}{\mathrm{L}}\right)^{1.11}[\mathrm{MPa}]
$$

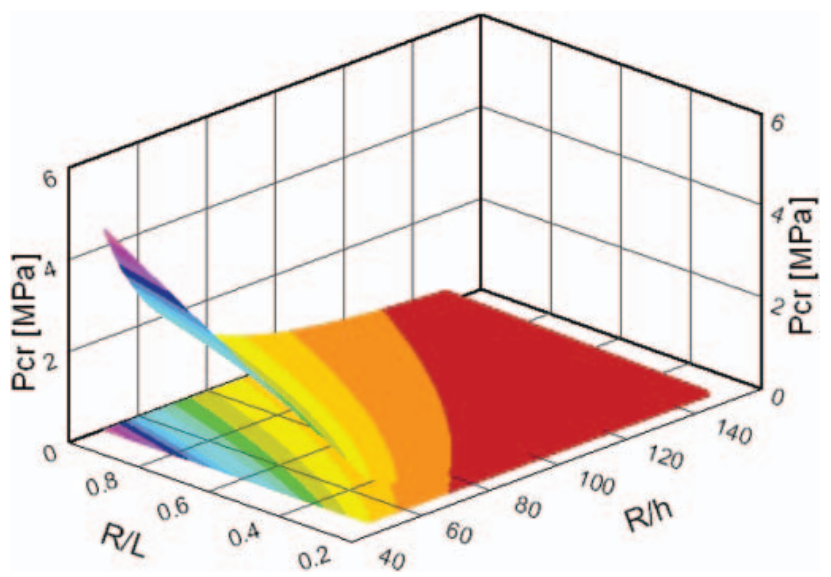

Fig. 3. Diagram of the relation $p_{c r}=f\left(\frac{R}{h}, \frac{R}{L}\right)$ - for structural material:AL-5083 alloy

\section{APPROXIMATION OF MINIMUM VALUE OF SHELL THICKNESS}

On the basis of Eq. and was obtained the set of discrete values of the converse problem consisting in determining geometrical parameters of vessel at an assumed operational submersion depth:

$$
\left(\frac{\mathrm{R}}{\mathrm{h}}\right)_{i}=\mathrm{f}\left(\left(\mathrm{p}_{\mathrm{cr}}\right)_{\mathrm{i}},\left(\frac{\mathrm{R}}{\mathrm{L}}\right)_{\mathrm{i}}\right)
$$

On the basis of the set of discrete values achieved from the relation (30) an analytical formula was elaborated by applying the method of least squares of deviations. In the case of steel vessels the best obtained approximation of critical pressure is represented by the following expression [6]:

$$
\frac{\mathrm{R}}{\mathrm{h}}=144745-5538 \cdot \mathrm{p}_{\mathrm{cr}}^{0.009869}+
$$

$-139075 \cdot\left(\frac{\mathrm{R}}{\mathrm{L}}\right)^{-0.00040244}+3.670 \cdot \mathrm{p}_{\mathrm{cr}}^{1.0916} \cdot\left(\frac{\mathrm{R}}{\mathrm{L}}\right)^{-1.1045}$

where:

$\mathrm{p}_{\mathrm{cr}}-$ given in $[\mathrm{MPa}]$.

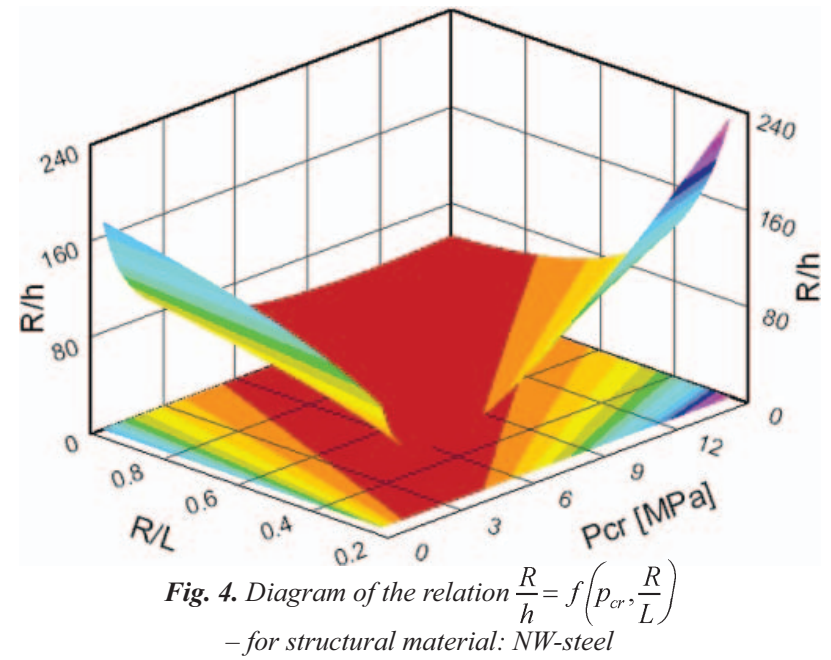

POLISH MARITIME RESEARCH, No 2/2010 
Tab. 1 .

\begin{tabular}{|c|c|c|c|c|c|}
\hline PARAMETER & & Variant I & Variant II & Variant III & Variant IV \\
\hline Assumptions & Unit of measure & Value & Value & Value & Value \\
\hline Structural material & - & Al-5083 & Al-5083 & St-235 & St-235 \\
\hline 0 - tight; 1 - flooded & - & 0 & 1 & 0 & 1 \\
\hline Material density & {$\left[\mathrm{t} / \mathrm{m}^{3}\right]$} & 2.7 & 2.7 & 7.85 & 7.85 \\
\hline Submersion depth & {$[\mathrm{m}]$} & 200 & 200 & 200 & 200 \\
\hline Mass of apparatus & {$[\mathrm{t}]$} & 0.15 & 0.15 & 0.15 & 0.15 \\
\hline Average density of apparatus & {$\left[\mathrm{t} / \mathrm{m}^{3}\right]$} & 1.5 & 1.5 & 1.5 & 1.5 \\
\hline Effective displacement & {$[\mathrm{t}]$} & 0.1 & 0.1 & 0.1 & 0.1 \\
\hline $\mathrm{R} / \mathrm{L}$ ratio & {$[-]$} & 1 & 1 & 1 & 1 \\
\hline $\mathrm{ld} / \mathrm{R}$ ratio & {$[-]$} & 0.5 & 0.5 & 0.5 & 0.5 \\
\hline Exponent $\mathrm{t}>2$ & {$[-]$} & 2.5 & 2.5 & 2.5 & 2.5 \\
\hline Young modulus & {$[\mathrm{MPa}]$} & 72000 & 72000 & 210000 & 210000 \\
\hline Poisson ratio & {$[-]$} & 0.33 & 0.33 & 0.3 & 0.3 \\
\hline Safety factor & {$[-]$} & 3 & 3 & 3 & 3 \\
\hline Life time & [year] & 5 & 5 & 5 & 5 \\
\hline Water density & {$\left[\mathrm{t} / \mathrm{m}^{3}\right]$} & 1.025 & 1.025 & 1.025 & 1.025 \\
\hline Foam density & {$\left[\mathrm{t} / \mathrm{m}^{3}\right]$} & 0 & 0.05 & 0 & 0.05 \\
\hline Results of calculations & Unit of measure & Value & Value & Value & Value \\
\hline Design pressure & {$[\mathrm{MPa}]$} & 6.03 & 6.03 & 6.03 & 6.03 \\
\hline Vessel diameter & {$[\mathrm{m}]$} & 0.754 & 0.895 & 0.820 & 1.293 \\
\hline Casing height & {$[\mathrm{m}]$} & 0.377 & 0.447 & 0.410 & 0.647 \\
\hline Shell plating thickness & {$[\mathrm{mm}]$} & 8.5 & 10.1 & 7.0 & 11.0 \\
\hline Vessel height & {$[\mathrm{m}]$} & 0.754 & 0.895 & 0.820 & 1.293 \\
\hline Bottom height & {$[\mathrm{m}]$} & 0.189 & 0.224 & 0.205 & 0.323 \\
\hline Bottom surface area & {$[\mathrm{m} 2]$} & 0.56 & 0.79 & 0.66 & 1.64 \\
\hline Casing surface area & {$[\mathrm{m} 2]$} & 0.894 & 1.258 & 1.056 & 2.627 \\
\hline Vessel surface area & {$[\mathrm{m} 2]$} & 2.012 & 2.831 & 2.379 & 5.914 \\
\hline Volume of two bottoms & {$\left[\mathrm{m}^{3}\right]$} & 0.120 & 0.200 & 0.154 & 0.605 \\
\hline Vessel volume & {$\left[\mathrm{m}^{3}\right]$} & 0.289 & 0.482 & 0.371 & 1.454 \\
\hline Vessel displacement & {$[\mathrm{kg}]$} & 295.8 & 337.1 & 380.1 & 788.7 \\
\hline Mass of vessel shell plating & {$[\mathrm{kg}]$} & 46.2 & 77.1 & 129.8 & 508.5 \\
\hline Mass of foam & {$[\mathrm{kg}]$} & 0.0 & 10.0 & 0.0 & 30.2 \\
\hline Total mass & {$[\mathrm{kg}]$} & 196.2 & 237.1 & 279.8 & 688.7 \\
\hline Effective displacement & {$[\mathrm{kg}]$} & 99.6 & 100.0 & 100.3 & 100.0 \\
\hline Axial stresses & {$[\mathrm{MPa}]$} & 133.8 & 133.9 & 178.0 & 178.1 \\
\hline Circumferential stresses & {$[\mathrm{MPa}]$} & 267.53 & 267.8 & 355.9 & 356.2 \\
\hline Reduced stresses & {$[\mathrm{MPa}]$} & 231.7 & 231.9 & 308.2 & 308.4 \\
\hline Permissible stresses & {$[\mathrm{MPa}]$} & 235.0 & 235.0 & 235.0 & 235.0 \\
\hline Minimum strength-based thickness & {$[\mathrm{mm}]$} & 8.4 & 9.9 & 9.1 & 14.4 \\
\hline Minimum permissible thickness & {$[\mathrm{mm}]$} & 8.5 & 10.1 & 9.1 & 14.4 \\
\hline Corrosion allowance & {$[\mathrm{mm}]$} & 0.25 & 0.25 & 0.25 & 0.25 \\
\hline Allowance for plate thickness manufacturing tolerance & {$[\mathrm{mm}]$} & 0.8 & 0.8 & 0.8 & 0.8 \\
\hline Allowance for other stresses & {$[\mathrm{mm}]$} & 0.25 & 0.25 & 0.25 & 0.25 \\
\hline Technological plating thickness & {$[\mathrm{mm}]$} & 10.0 & 11.0 & 10.0 & 16.0 \\
\hline Mass of vessel after thickness correction & {$[\mathrm{kg}]$} & 54.3 & 84.1 & 138.0 & 546.2 \\
\hline Total mass after thickness correction & {$[\mathrm{kg}]$} & 204.3 & 234.1 & 288.0 & 696.2 \\
\hline Effective displacement after thickness correction & {$[\mathrm{kg}]$} & 96.3 & 107.7 & 95.1 & 101.4 \\
\hline
\end{tabular}


In the case of vessels made of AL-5083 alloy the best approximation of critical pressure, within the range of considered design parameters, is represented by the following expression [6]:

$$
\frac{\mathrm{R}}{\mathrm{h}}=5.682+82.78 \cdot \mathrm{p}_{\mathrm{cr}}{ }^{-0.4234} \cdot\left(\frac{\mathrm{R}}{\mathrm{L}}\right)^{0.4533}
$$

where:

$\mathrm{p}_{\mathrm{cr}}$ - given in $[\mathrm{MPa}]$.

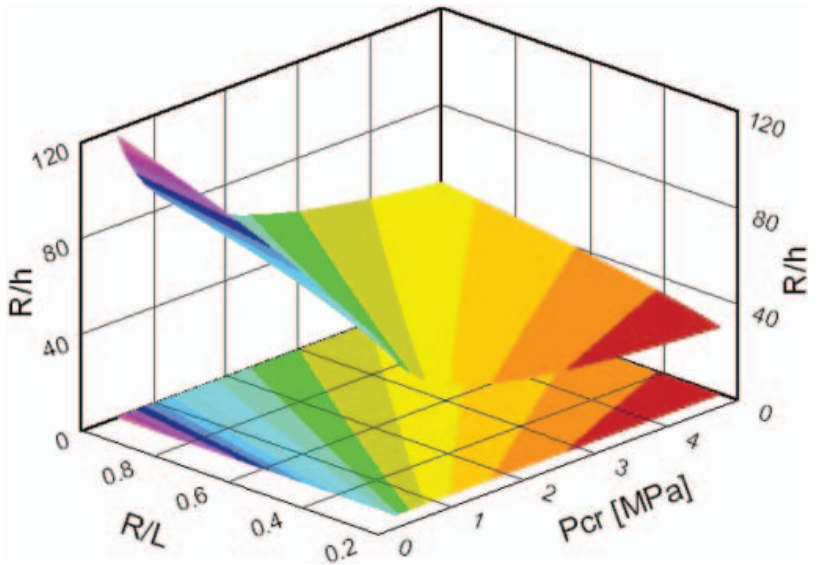

Fig. 5. Diagram of the relation $\frac{R}{h}=f\left(p_{c r}, \frac{R}{L}\right)$

- for structural material: AL-5083 alloy

\section{RECAPITULATION AND EXAMPLE OF APPLICATION OF THE METHOD}

By substituting, to the buoyancy equation, the approximation formulae for $\mathrm{V}\left(\mathrm{R}_{\mathrm{p}}, \mathrm{L}_{\mathrm{p}}, \mathrm{L}_{\mathrm{d}}\right), \mathrm{S}\left(\mathrm{R}_{\mathrm{p}}, \mathrm{L}_{\mathrm{p}}, \mathrm{L}_{\mathrm{d}}\right), \mathrm{h}\left(\mathrm{R}_{\mathrm{p}}, \mathrm{L}_{\mathrm{p}}, \mathrm{p}_{\mathrm{cr}}\right)$ and $\mathrm{p}_{\mathrm{cr}}(\mathrm{R} / \mathrm{h}, \mathrm{R} / \mathrm{L})$, the balance is obtained of mass and displacement components of vessel, expressed explicite by its design parameters and design assumptions, as follows:

$$
\begin{gathered}
(1-\alpha) \cdot \rho_{w} \cdot V\left(R, L, L_{d}\right)-S\left(R, L, L_{d}\right) \cdot \\
\cdot h\left(R, L, p_{c r}\right) \cdot \rho_{v}-m_{a}-V_{f} \cdot \rho_{f}+\alpha \cdot \rho_{w} \cdot \\
\cdot\left(\frac{m_{a}}{\rho_{a}}+V_{f}+S\left(R, L, L_{d}\right) \cdot h\left(R, L, p_{c r}\right)\right)-D_{e}=0
\end{gathered}
$$

Solution of the design problem in question is reached by numerical solving the buoyancy equation supplemented by relevant assumptions on requirements and conditions for a given case.

\section{Example of application of the method}

It has to be designed a vessel made of AL-5083 alloy or NW steel, capable of accommodating apparatus of the average density of $1.5 \mathrm{t} / \mathrm{m}^{3}$ and $100 \mathrm{~kg}$ mass, intended for operation at $200 \mathrm{~m}$ submersion depth in the water of $1.025 \mathrm{t} / \mathrm{m}^{3}$ density, so as to obtain the vessel's effective displacement of about $100 \mathrm{~kg}$. Alternatively it should be considered the case of a vessel of foam-filled bottoms, so as to obtain, but after flooding its interior, the same effective displacement of about $100 \mathrm{~kg}$.

The supplementary assumptions and determined values of the design parameters are contained in Tab. 1.

Note: This research has been performed in the frame of the R\&D project No. PR NR O R00 004708 financed by the Ministry of Science and Higher Education from its resources for the years 2009-2011

\section{NOMENCLATURE}

D - effective displacement

$\mathrm{E}^{\mathrm{e}}$ - Young modulus

$\mathrm{F}_{\mathrm{z}}$ - value of external concentrated load

$\mathrm{g}$ - gravity acceleration

h - shell plating thickness

L - length of casing (cylindrical part of a vessel)

$1_{d}$ - bottom camber

$\mathrm{m}_{\mathrm{a}}$ - mass of apparatus

$\mathrm{m}_{\mathrm{f}}$ - mass of filler (foam)

$m_{v}$ - mass of vessel shell plating

$\mathrm{N}_{\varphi}$ - circumferential force per unit of vessel directrix length

$\mathrm{N}_{z}^{\varphi}$ - axial force per unit of vessel circumference length

$n_{\mathrm{s}}$ - value of safety factor

$\mathrm{R}$ - casing curvature radius

$R_{e} \quad$ - material yield point

$\mathrm{R}^{\mathrm{e}}$ - circumferential curvature radius

$\mathrm{R}_{\mathrm{z}}$ - axial curvature radius

$\mathrm{r}$ - radial variable

$\mathrm{S}$ - vessel surface area

$\mathrm{S}_{\mathrm{d}}$ - bottom surface area

$\mathrm{t}$ - power exponent

$\mathrm{V}$ - vessel volume

z - axial variable

$\alpha \quad$ - index of vessel's variant (tight or flooded)

$\Delta \mathrm{R}$ - quadrature step

$\mathrm{V}$ - Poisson ratio

$\sigma_{\text {red }}-$ reduced stresses

$\sigma_{z}-$ axial stresses

$\sigma_{\varphi}^{z}$ - circumferential stresses

$\rho_{\mathrm{a}} \quad$ - average density of apparatus

$\rho_{\mathrm{f}}$ - filler density

$\rho_{\mathrm{v}} \quad$ - vessel plating density

$\rho_{\mathrm{w}}$ - water density

$\xi^{\mathrm{w}}$ - dimensionless radial variable

$\zeta$ - dimesionless axial variable.

\section{BIBLIOGRAPHY}

1. Timoshenko S.: Theory of elastic stability. McGraw-Hill Book Co. New York 1936

2. Bochenek B., Krużelecki J.: Optimization of stability of structures (in Polish). Wydawnictwo Politechniki Krakowskiej (Publishing House of Cracow University of Technology), Cracow 2007

3. Rowiński L.: Underwater vehicles - construction and equipment (in Polish). „WiB” Publishers, Gdańsk 2008

4. Magnucki K.: Strength and optimization of pressure vessels (in Polish). Wydawnictwo Naukowe PWN (Polish Scientific Publishing House). Warsaw 1998

5. Michalski J.P.: A study on identification of elements of a set of design assumptions for an autonomous echo-location module (in Polish). Prace Naukowo-Badawcze W.O.i O. PG No.03/PR/2010 (Scientific reports of Faculty of Ocean Engineering and Ship Technology, Gdańsk University of Technology), Gdańsk 2010

6. Michalski J.P.: Elaboration and testing of calculation algorithms useful in formulating a method for the preliminary designing of structure of echo-location module (in Polish). Prace NaukowoBadawcze W.O.i O. PG No.04/PR/2010 (Scientific reports of Faculty of Ocean Engineering and Ship Technology, Gdańsk University of Technology), Gdańsk 2010.

\section{CONTACT WITH THE AUTHOR}

Assoc. Prof. Jan P. Michalski

Faculty of Ocean Engineering and Ship Technology

Gdansk University of Technology Narutowicza 11/12

80-233 Gdansk, POLAND

e-mail: janmi@pg.gda.pl 